九州大学学術情報リポジトリ

Kyushu University Institutional Repository

\title{
Evaluation of Mitigation Effect of the Upland Field on the Regional Environment
}

Yuge, Kozue

Faculty of Agriculture, Kyushu Unviersity

Oohira, Yutaka

Graduate School of Bioresource and Bioenvironmental Sciences, Kyushu Unviersity

Hao, Aimin

Graduate School of Bioresource and Bioenvironmental Sciences, Kyushu Unviersity

Nakano, Yoshisuke

Faculty of Agriculture, Kyushu Unviersity

https://doi.org/10.5109/4687

出版情報：九州大学大学院農学研究院紀要. 50 (2)，pp.791-797，2005-10-01. Faculty of Agriculture, Kyushu University

バージョン：

権利関係 : 


\title{
Evaluation of Mitigation Effect of the Upland Field on the Regional Environment
}

\author{
Kozue YUGE*, Yutaka OOHIRA ${ }^{1}$, Aimin HAO ${ }^{1}$ \\ and Yoshisuke NAKANO
}

\author{
Laboratory of Irrigation and Water Utilization, Division of Regional Environment Science, \\ Department of Bioproduction Environmental Sciences, Faculty of Agriculture, \\ Kyushu University, Fukuoka 812-8581, Japan \\ (Received June 29, 2005 and accepted July 26, 2005)
}

\begin{abstract}
The objective of this study is the evaluation of the mitigation effect of the upland field on the regional intrinsic environment, considering the crop growth stages. FAO Penman-Monteith method is introduced for calculation of the reference evapotranspiration. The crop transpiration and the soil surface evaporation in the upland fields are separately estimated using the crop coefficients, considering the crop growth stages. The ratios of the crop transpiration and the soil surface evaporation in the water consumption change drastically with the crop growth stages. To evaluate the mitigation effect of the upland field, the latent heat fluxes in the sugar cane field and bare field are estimated during the crop growth period. The deference of the latent heat fluxes in the sugar cane field and the bare field is not marked in the initial crop growth stages. However, in the sugar cane field, the latent heat flux increases drastically, with the sugar cane growing. In the mid-season stage, the latent heat flux is larger than the net radiation. These results indicate that the crop field has the large mitigation effect on the environment, and the efficiency changes with the various factors, including the crop types, the crop growth stages, the cultivation condition, and so on.
\end{abstract}

\section{INTRODUCTION}

The water consumption in the upland fields is evapotranspiration and the surface runoff. When the water is consumed by the evapotranspiration, the latent heat is consumed for the water vaporization. Especially, the latent heat flux is large in the irrigated crop field, because the large amount water is consumed as the evapotranspiration. It can be considered as the mitigation effect on the regional intrinsic environment, and one of the most important multi-functions of the farmland.

The studies of the various multi-functions have been conducted by many researchers. The actual condition of multi-function of irrigation water is reported by Shima and Tsutsumi (2004). Takimoto (2004) reported the various multi-functions of the paddy field. Shinogi (2004) shows the preliminary study of the multi-functions in the upland field. These studies clarify the multi-functions in the farmland or agricultural facilities. However few papers on the quantitative evaluation of the multi function in the upland field have been published.

\footnotetext{
1 Laboratory of Irrigation and Water Utilization, Division of Regional Environment Science, Department of Bioproduction Environmental Sciences, Graduate School of Bioresource and Bioenvironmental Sciences, Kyushu University

* Corresponding author (E- mail: yuge@bpes.kyushu-u.ac.jp)
} 
The objective of this study is the evaluation of the mitigation effect of the upland field on the regional intrinsic environment. The mitigation effect is affected on the various factors, including the crop types, crop growth stages, irrigation schedule, soil water content, meteorological conditions, and so on. To evaluate the mitigation effect of the upland field considering these factors, the FAO Penman-Monteith method is introduced for calculation of the reference evapotranspiration. Next, the crop transpiration and soil surface evaporation are separately estimated using the dual crop coefficients considering the crop growth stages. Using the result, the latent heat flux in the upland field is estimated during the crop growth period.

\section{STUDY SITE}

Evapotranspiration is quantified in Haneji-Ookawa area (N24 $\left.{ }^{\circ} 55^{\prime}, \mathrm{E} 127^{\circ} 56^{\prime}\right)$, which is located in north of Okinawa Prefecture (southwest of Japan), as shown in Fig. 1. The climate of the study site is classified as sub-tropic climate. The areas of the paddy field and upland field at the study site are about $144 \mathrm{ha}$ and $1000 \mathrm{ha}$, respectively. The staple agricultural product is sugar cane. The drought occurs frequently and the agricultural product is damaged, because the improvement of the irrigation facilities has been insufficient and the rainfall condition changes drastically every year. The soil of the study site is classified as the maaji soil. The maaji soil is acid, and shows the low water retention.

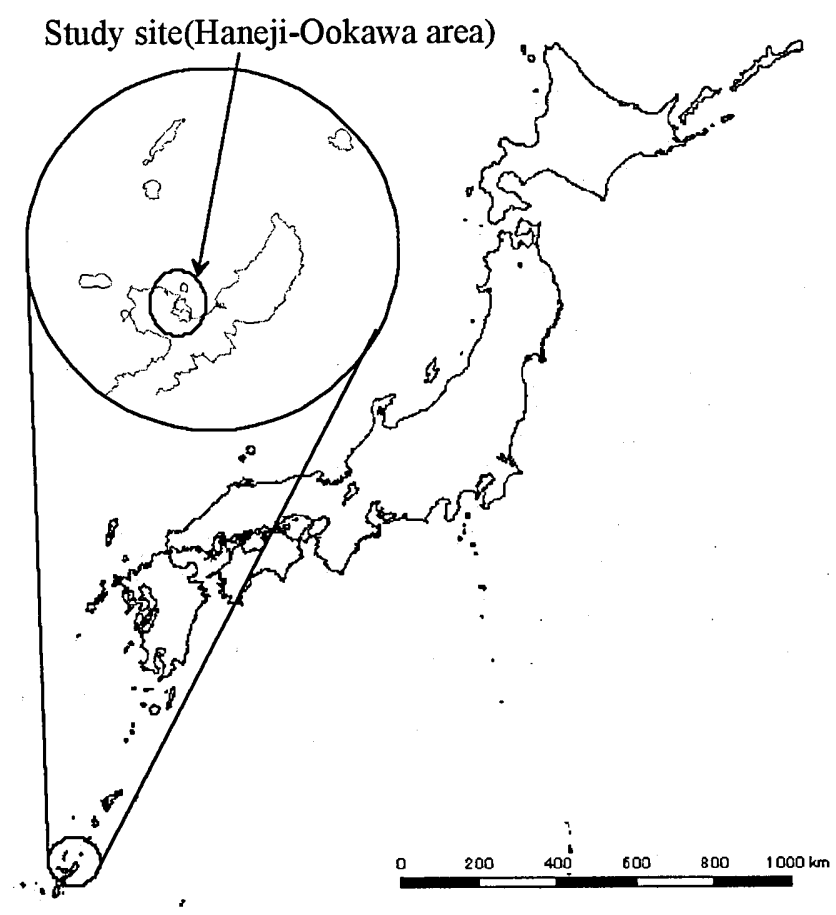

Fig. 1. Location of the study site. 


\section{METHODROGY}

\section{Estimation of the evapotranspiration using the FAO Penman-Monteith Method}

In this study, the evapotranspiration is calculated using the method suggested by Allen et al. (1998).

Evapotranspiration in the crop field can be estimated as follows:

$$
E T_{c}=K_{c} E T_{0}
$$

where $K_{c}$ is the crop coefficient, $E T_{0}$ is the reference evapotranspiration(mm day $\left.{ }^{-1}\right), E T_{c}$ is the evapotranspiration in the crop field $\left(\mathrm{mm}^{\mathrm{day}}{ }^{-1}\right)$.

Eq. (1) can be described as follows, because the evapotranspiration is composed of the soil surface evaporation and the crop transpiration.

$$
E T_{c}=\left(K_{c b}+K_{e}\right) E T_{0}
$$

where $K_{c b}$ is the basal crop coefficient, $K_{e}$ is the evaporation coefficient.

The latent heat flux $E\left(\mathrm{MJ} \mathrm{m}^{-2}\right.$ day $\left.^{-1}\right)$ can be estimated as follows:

$$
E=L \cdot E T_{c}
$$

where $L$ is the latent heat of the water vaporization $\left(\mathrm{MJ} \mathrm{kg}^{-1}\right)$.

$E T_{0}$ have been estimated using various methods, including Penman Method or Penman-Monteith Method. In this study, FAO Penman-Monteith method suggested by Allen et al. (1998) is adopted to estimate $E T_{0}$.

$$
E T_{0}=\frac{0.408 \Delta\left(R_{n}-G\right)+\gamma \frac{900}{T_{a}+273} u_{2}\left(e_{s}-e_{a}\right)}{\Delta+\gamma\left(1+0.34 u_{2}\right)}
$$

where $R_{n}$ is the net radiation at the crop surface $\left(\mathrm{MJ} \mathrm{m}^{-2}\right.$ day $\left.^{-1}\right), G$ is the ground heat flux $\left(\mathrm{MJ} \mathrm{m}^{-2}\right.$ day $\left.^{-1}\right), T_{a}$ is the air temperature $\left({ }^{\circ} \mathrm{C}\right), u_{2}$ is the wind velocity $\left(\mathrm{m} \mathrm{s}^{-1}\right), e_{s}$ is the saturation vapor pressure $(\mathrm{kPa}), e_{a}$ is the actual vapor pressure $(\mathrm{kPa}), \gamma$ is the psychrometric constant $\left(\mathrm{kPa}^{\circ} \mathrm{C}^{-1}\right), \Delta$ is the slope vapor pressure curve $\left(\mathrm{kPa}^{\circ} \mathrm{C}^{-1}\right)$.

\section{Parameter Estimation for FAO Penman-Monteith Method}

Radiation components

The net radiation at the crop surface $R_{n}$ can be estimated as follows:

$$
R_{n}=R_{n s}-R_{n l}
$$

where $R_{n s}$ is the shortwave radiation at the crop surface (MJ m-2 day-1), and $R_{n l}$ is the longwave radiation emitted from the crop surface $\left(\mathrm{MJ} \mathrm{m}^{-2}\right.$ day $\left.^{-1}\right)$.

These components can be estimated by the following equations. 


$$
\begin{aligned}
& R_{n a}=(1-\alpha) R_{s} \\
& R_{n l}=\sigma\left(\frac{\left(T_{\max }+273\right)^{4}+\left(T_{\min }+273\right)^{4}}{2}\right)\left(0.34-0.14 \sqrt{e_{a}}\right)\left(1.35 \frac{R_{s}}{R_{s o}}-0.35\right)
\end{aligned}
$$

where $R_{s}$ is the total solar radiation, $\alpha$ is the albedo, $\sigma$ is the Stefan-Boltsmann constant $\left(=4.903 \times 10^{-9} \mathrm{MJ} \mathrm{K}^{-4} \mathrm{~m}^{-2}\right.$ day $\left.^{-1}\right), T_{\max }$ is the daily maximum temperature $\left({ }^{\circ} \mathrm{C}\right), T_{\min }$ is the daily minimum temperature, $R_{s o}$ is the clear-sky radiation $\left(\mathrm{MJ} \mathrm{m}^{-2}\right.$ day $\left.^{-1}\right)$.

When the measured total solar radiation $R_{s}$ and the clear-sky radiation $R_{s o}$ can not be obtained, these parameters are estimated as follows:

$$
\begin{aligned}
& R_{s}=\left(0.25+0.5 \frac{n}{N}\right) R_{a} \\
& R_{s o}=\left(0.75+2 \cdot 10^{-5} z\right) R_{a}
\end{aligned}
$$

where $n$ is the actual duration of sunshine (hour), $N$ is the maximum possible duration of sunshine (hour), $R_{a}$ is the extraterrestrial radiation $\left(\mathrm{MJ} \mathrm{m}^{-2}\right.$ day $\left.{ }^{-1}\right), z$ is the measurement elevation above the sea level (m). $R_{a}$ can be estimated from the solar constant, the solar declination, and the geographic relationship between the ground surface and the sun.

Daily ground heat flux beneath the crop canopy $G$ can be ignored, because the value is relatively small.

\section{Other parameters}

The saturation vapor pressure $e_{s}$, the actual vapor pressure $e_{a}$, the psychrometric constant $\gamma$, and the slope vapor pressure curve $\Delta$ can be calculated as follows:

$$
\begin{aligned}
e_{s} & =\frac{e^{o}\left(T_{\text {max }}\right)+e^{o}\left(T_{\text {min }}\right)}{2} \\
e_{a} & =\frac{R H_{\text {mean }}}{100} e_{s} \\
& =\frac{R H_{\text {mean }}}{100}\left[\frac{e^{o}\left(T_{\text {max }}\right)+e^{o}\left(T_{\text {min }}\right)}{2}\right] \\
\Delta & =\frac{4098\left[0.6108 \exp \left(\frac{17.27 T_{a}}{T_{a}+237.3}\right)\right]}{\left(T_{a}+237.3\right)^{2}}
\end{aligned}
$$

where $e^{\circ}\left(T_{a}\right)$ is the saturation vapor pressure at the air temperature $T_{a}, R H_{\text {mean }}$ is the mean relative humidity, $T_{\max }$ is the daily maximum temperature, and $T_{\min }$ is the daily minimum temperature.

The value of $e^{\circ}\left(T_{a}\right)$ can be estimated as follows: 


$$
e^{o}\left(T_{a}\right)=0.6108 \exp \left(\frac{17.27 T_{a}}{T_{a}+237.3}\right)
$$

\section{Crop coefficient}

Allen et al. (1998) reported that the crop coefficient changes with the crop growth stages which are classified as the initial, development, mid-season, and late season stages. The crop coefficients of the initial, mid-season, and late season stages for various crops are experimentally estimated.

From eqs. (1) and (2), the crop coefficient can be described by as follows, because the evapotranspiration can be composed of the crop transpiration and the soil surface evaporation.

$$
K_{c}=K_{c b}+K_{e}
$$

$K_{c b} \mathrm{~S}$ of the various crops in the initial, mid-season, and late season stages is reported by Allen et al. (1998). The crop growth stages at the study site are inferred using the cultivation guideline of the sugar cane reported by Okinawa Prefecture (1999). The value of $K_{e}$ can be estimated, considering the metrological and soil water conditions. In this study, however, the value of $K_{e}$ is calculated by subtracting $K_{c b}$ from the $K_{c}$. The values of $K_{c b}$ and $K_{e}$ are through the sugar cane growth period are shown in Fig. 2.

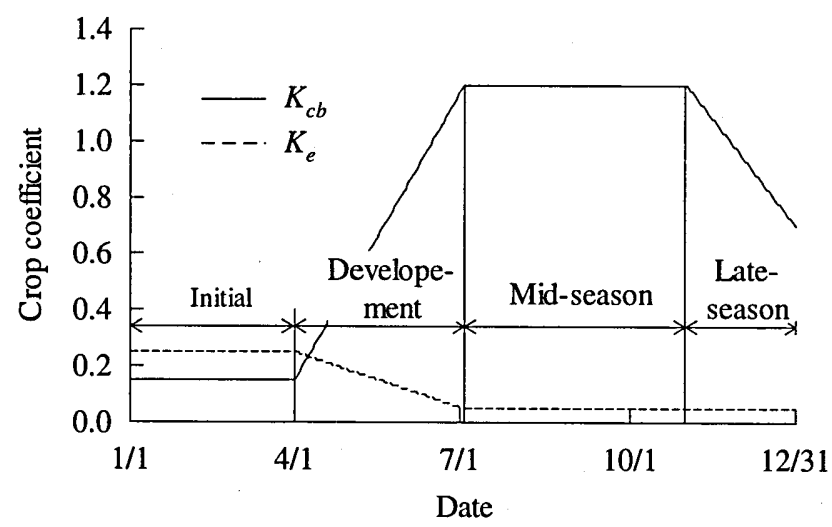

Fig. 2. Basal crop coefficient and evaporation coefficient of the sugar cane.

\section{RESULTS AND DISCUSSION}

The reference evapotranspiration at the study site is quantified using the meteorological data observed in the Naha weather station. The ground heat flux $G$ can be neglected because the amount of $G$ is very small, comparing with the net radiation at the crop surface $R_{n}$. To evaluate the mitigation effect of the upland field, the crop transpi- 
ration and soil surface evaporation in the upland field are quantified by multiplying the reference evapotranspiration by the crop coefficients shown in Fig. 2.' The crop cultivated in the upland field of the study site is assumed as the sugar cane. The basal crop coefficient and evaporation coefficient are specified, considering the crop growth stages as shown in Fig. 2.

Figure 3 shows the daily changes of the crop transpiration and soil surface evaporation estimated by eq.(2). In the initial crop growth stage, the soil surface evaporation is relatively large, comparing with the amount of the crop transpiration. The soil surface evaporation gradually decreases, with the crop growth, because the solar radiation reaches the soil surface is intercepted when the crop canopy is dense. On the other hand, the crop transpiration increases gradually with the crop growth. In the mid-season of the crop growth stage, the crop transpiration is twenty times of the soil surface evaporation.

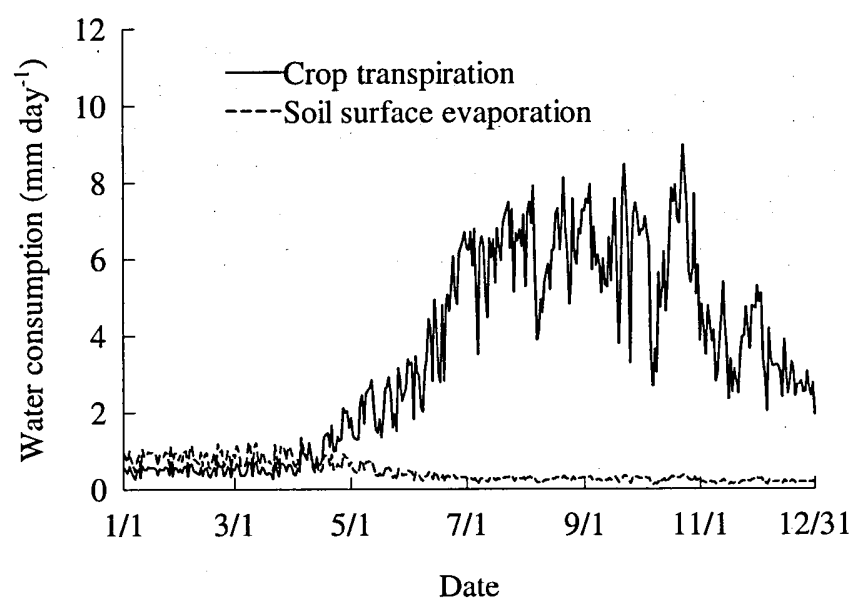

Fig. 3. Daily changes of crop transpiration and soil surface evaporation in the sugar cane field.

To evaluate the mitigation effect of the upland field, the latent heat fluxes in the sugar cane field and bare field are estimated. In the bare field, the basal crop coefficient is set as 0 , and the evaporation coefficient is assumed same as the value in the initial crop growth stage shown in Fig. 2, 0.25. Figure 4 shows the monthly averages of the solar radiation, net radiation, latent heat fluxes of the sugar cane field and the bare field. This figure indicates that the deference of the latent heat fluxes in the sugar cane and the bare field is not marked in the initial crop growth stage. However, the latent heat flux increases drastically, with the sugar cane growing. In the mid-season stage, the latent heat flux is larger than the net radiation.

\section{CONCLUSIONS}

To evaluate the mitigation effect of the upland field, the FAO Penman-Monteith 


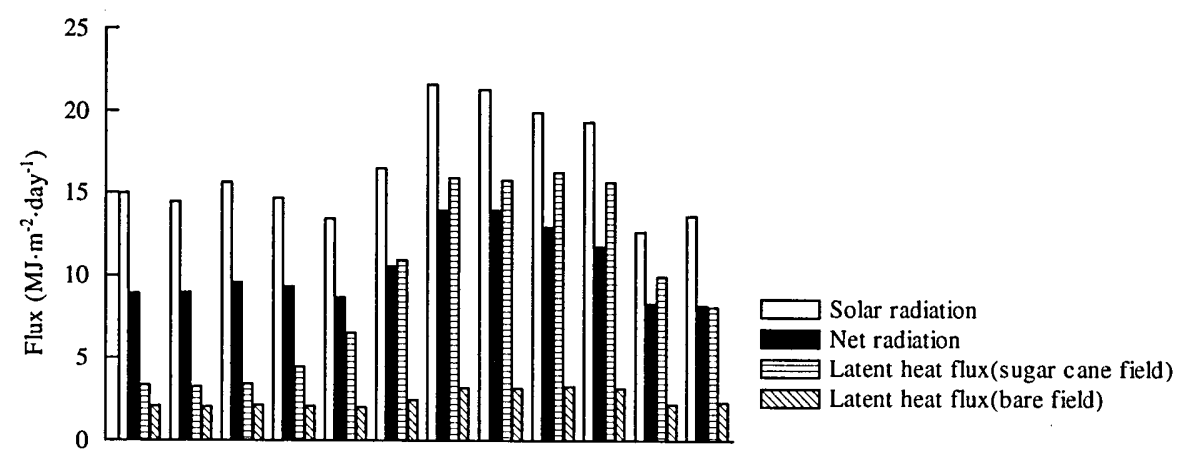

Jan. Feb. Mar. Apr. May Jun. Jul. Aug. Sep. Oct. Nov. Dec.

Fig. 4. Monthly averages of the solar radiation, net radiation, and latent heat flux.

method is introduced to quantify the reference evapotranspiration using the meteorological data. The crop transpiration and the soil surface evaporation in the upland field are separately calculated using the crop coefficients, considering the crop growth stages. In the initial crop growth stage, the most of the water consumption is the soil surface evaporation, and the amount of the soil surface evaporation decreases gradually with the crop growing. The crop transpiration increase gradually, with the crop growth stages. In the mid-season of the crop growth stage, the crop transpiration is twenty times of the soil surface evaporation.

To evaluate the mitigation effect of the upland field, the latent heat fluxes in the sugar cane field and bare field are estimated during the crop growth period. The deference of the latent heat fluxes in the sugar cane field and the bare field is not marked in the initial crop growth stage. However, the latent heat flux increases drastically, with the sugar cane growing. In the mid-season stage, the latent heat flux is larger than the net radiation. These results indicate that the crop field has the large mitigation effect on the environment, and the efficiency changes with the various factors, including the crop types, the crop growth stages, the cultivation condition, and so on. The method introduced here is effective to evaluate the mitigation effect of the crop field, considering these factors.

\section{REFERENCES}

Allen, R. G., L. S. Pereira, D. Raes and M. Smith 1998 Crop evapotranspiration -Guidelines for computing crop water requirements-. FAO irrigation and drainage, 56: 87-158

Okinawa Prefecture 1999 Cultivation guideline of the sugar cane. Okinawa Prefecture (In Japanese)

Shima, E. and S. Tsutsumi 2004 Actual condition and problems of murmuring of the stream canal in multi function of irrigation water. Jour. JSIDRE, 72(7): 575-578 (In Japanese)

Shinogi, Y. 2004 Preliminary research of rural resurces and multi-functional role of upland (non-rice paddy). Jour. JSIDRE, 72(8): 663-666 (In Japanese)

Takimoto, T. 2004 Multi-functional roles of paddy irrigation in monsoon Asia. Jour. JSIDRE, 72(7): 559-564 (In Japanese) 